\title{
Produção Científica sobre Saúde Mental de Idosos Residentes em Instituições de Longa Permanência
}

Samara Maria de Jesus Veras ${ }^{1}$; Werika Shirley Beserra da Silva ${ }^{1}$; Cláudia Daniele Barros Leite Salgueiro².

\begin{abstract}
Introdução: Trata-se de uma revisão integrativa sobre a saúde mental de idosos residentes em Instituições de Longa Permanência para Idosos (ILPIs). Objetivo: O estudo buscou evidenciar o perfil dos trabalhos publicados em âmbito nacional, no período de 2000 a 2016, com o levantamento feito a partir do Portal Regional da Biblioteca Virtual de Saúde (BVS), direcionando para periódicos indexados nas bases LILACS e SciELO. Método: A amostra foi apresentada em um quadro sinótico com a distribuição dos artigos analisados. Considerações finais: Os autores encontraram ampla discussão na literatura, principalmente considerando-se aspectos relacionando moradia, falta de acompanhamento familiar, sentimentos e predisposição à depressão. Observou-se enfoque na reflexão sobre aspectos biopsicossociais e familiares pregressos e atuais na vida do idoso como também, a avaliação da qualidade de vida de idosos residentes em ILPIs e a prestação de serviço de profissionais de saúde visando promover a integralidade dos cuidados gerontológicos aos idosos residentes em ILPIs.
\end{abstract}

Descritores: Envelhecimento; Saúde Mental; Instituição de Longa Permanência para Idosos; Cuidadores.

\section{Scientific Production on Mental HealthiIn Elderly Residents in Long Term Care}

Introduction: This is an integrative review on the mental health of elderly people living in Long-Term Care Facilities for the Elderly (ILPIs). Objective: The study aimed to highlight the profile of the works published in the national context, from 2000 to 2016, with a survey made from the Regional Portal of the Virtual Health Library (VHL), targeting indexed journals in the LILACS and SciELO databases. Method: The sample was presented in a synoptic table with the distribution of the articles analyzed. Conclusion: The authors found extensive discussion in the literature, especially considering aspects relating to housing, lack of family support, feelings and predisposition to depression. It was observed a focus on the reflection on biopsychosocial aspects and previous and current family members in the life of the elderly, as well as the evaluation of the quality of life of the elderly living in ILPIs and the service delivery of health professionals aiming to promote the integrality of gerontological care for the elderly residents of ILPIs.

Keywords: Aging; Mental health; Institution of Long Stay for the Elderly; Caregivers.

${ }^{1}$ Discentes do curso de bacharelado em enfermagem - Instituto Federal de Educação, Ciência e Tecnologia de Pernambuco (IFPE) - Campus Pesqueira.

${ }^{2}$ Doutora em Psicologia Clínica pela Universidade Católica de Pernambuco (UNICAP), Mestra em Ciências da Saúde pela Universidade de Pernambuco (UPE), Pós Graduada em Saúde Coletiva pela mesma Universidade. Psicóloga formada pela Universidade Católica de Pernambuco (UNICAP). Docente do curso Bacharelado em Enfermagem do Instituto Federal de Educação, Ciência e Tecnologia de Pernambuco (IFPE) - Campus Pesqueira. Contato: claudia.leite @ pesqueira.ifpe.edu.br.

336 Id on Line Rev. Mult. Psic. V.12, N. 40. 2018 - ISSN 1981-1179 / DOI: 10.14295/idonline.v12i40.1050 Edição eletrônica em http://idonline.emnuvens.com.br/id 


\section{Introdução}

Nos métodos de intervenções aplicadas pelas sociedades ocidentais que enfrentam o fenômeno do envelhecimento, são incluídas, na sua gênese, premissas clássicas no âmbito da gerontologia, que solicita por uma maior atenção voltada para este público (RIBEIRO, 2012).

A concepção de jovialidade relacionada ao Brasil vem mudando nas últimas décadas, considerando que o país já foi sinônimo de juventude em todo o mundo, o envelhecimento populacional é um fenômeno que está diretamente relacionado com a transição de um país em desenvolvimento, para um país de Primeiro mundo. (VERAS, 2012).

Envelhecer, é um processo biológico inerente à pessoa humana, tal processo faz parte da manutenção da fisiologia do idoso. pessoas com mais de 60 anos, que está susceptível a danos provocados por agentes externos. Geralmente, este segmento populacional, apresenta maior quantidade de problemas advindos de doenças crônicas, em relação ao restante da população (SANTOS, 2013).

A transição demográfica apresentada mundialmente, estabelece que há um significativo aumento na proporção de idosos com 80 anos ou mais, modificando um cenário populacional com implicações importantes em diversas áreas, especialmente na saúde e qualidade de vida. Esse público etário apresenta de um modo geral, maior incidência de comorbidades e de declínio funcional (LOURENÇO et.al, 2012).

Assim sendo, os cuidados em Instituições de Longa Permanência para Idosos (ILPIs) poderão ser cada vez mais solicitados devido ao envelhecimento populacional à diminuição da taxa de fecundidade e à ascensão das mulheres no mercado de trabalho (CAMARANO, 2010; IBGE, 2010). Além disso, durante o processo de envelhecimento, são verificadas diversas alterações fisiológicas e de comorbidades, aumentando assim, a necessidade de cuidado profissional integral e especializado (LISBOA, 2012).

Não há dúvidas que o crescente índice populacional de idosos vem impulsionando o aumento numérico das Instituições de Longa Permanência para Idosos (ILPIs). Assim, em 2005 o Ministério da Saúde sancionou a Resolução da Diretoria Colegiada - RDC nº 283, de 26 de setembro, que aprova o regulamento técnico, definindo as normas para funcionamento adequado das ILPIs e assegurando os direitos das pessoas idosas, concernentes na Portaria 2.528/GM de 2006, que dentre os assuntos abordados na política ao público alvo, aborda a promoção do envelhecimento com qualidade, saúde e manutenção máxima da aptidão funcional pelo maior tempo plausível (BRASIL, 2005). 
Nestas Instituições, busca-se desenvolver um sistema que supra as demandas dos idosos através de uma equipe multiprofissional comprometida e estrutura satisfatória para efetivar a melhor assistência, comodidade e cuidado ao idoso, retirando aos poucos, os aspectos negativos desenvolvidos no imaginário e histórico popular (ZAGONEL et al., 2017; CORTELLETI; CASARA; HEREDIA, 2010).

Através das ILPIs, é possível ter acesso a um atendimento integral aos idosos dependentes ou não de cuidados específicos e independentemente de possuir uma família presente. As ILPI são definidas como: residência em república; atendimento em centro-dia; e atendimento em centro de convivência (CAMARANO, 2010; VIEIRA, 2010).

Neste mesmo cerne, torna-se mister salientar que ainda há discursos de preconceitos e estigmas relacionados às ILPIs. Há um preconceito em relacionar as instituições a locais de prisão, abandono, pobreza ou local onde os idosos ficam por não terem uma família disponível para cuidar deles, podem desencadear no idoso uma possível aversão à permanência e até mesmo à existência desses serviços nas comunidades (ZAGONEL et al., 2017), entretanto, a estigmatização social vem sendo vencida com a oferta de bons serviços públicos e particulares. Assim, as ILPIs se configuram como locais que tornam mais evidentes e agravantes as necessidades e dificuldades emocionais dos idosos como o transtorno depressivo (MATOS; OLCHIK, 2016).

Visto que a população idosa está inclusa nas variáveis de vulnerabilidade em função da sensibilidade relativa ao processo de envelhecimento, o tema idoso tem ganhado maior relevância enquanto objeto de estudo, com atenção especial para as comorbidades psiquiátricas, que vem aumentando com o passar dos anos, principalmente a depressão (ROESLER,2012).

Instabilidade financeira e declínio da saúde aumenta a dependência da família, momento este que se faz necessário manter uma aproximação considerável, a fim de evitar maiores danos à integridade física e psicológica do idoso, porém, há situações em que este papel e compromisso não é bem acolhido pela família do mesmo. Em casos com essa configuração, a institucionalização parece ser a única opção viável. A institucionalização aparece então, como opção bastante procurada. O idoso institucionalizado é obrigado a adaptar-se à rotina de horários, a dividir seu ambiente com desconhecidos e à distância da família. A individualidade e o poder de escolha são substituídos pelo sentimento de ser apenas mais um naquela coletividade (PORCU, 2002).

Entre os transtornos psiquiátricos que ocorre com mais frequência em idosos, está a depressão, doença silenciosa e por muitas vezes negligenciada. Partindo do princípio de que a

338 Id on Line Rev. Mult. Psic. V.12, N. 40. 2018 - ISSN 1981-1179 Edição eletrônica em http://idonline.emnuvens.com.br/id 
depressão é uma doença desencadeada por múltiplos fatores, tais como problemas sociais, culturais, biológicos e psicológicos, a observação dos fatores citados, aumenta as chances dos idosos envolvidos, terem menos comprometimento físico e consequentemente não culminar para o suicídio, a partir da identificação precoce do problema. (FERREIRA et al, 2013).

Considerando que transtornos depressivos são agravos que aumentam o comprometimento da saúde, diminui a qualidade de vida e são considerados problemas de grande magnitude a nível de saúde pública, pelas grandes taxas de morbidade e mortalidade, o comprometimento emocional, embotamento afetivo e diminuição da qualidade de vida oriundos de crises depressivas, acontecem com bastante frequência entre os idosos, público este que está à mercê da vulnerabilidade multicausal. (MINGHELLI et al, 2013).

Não obstante, faz-se necessário buscar as causas determinantes de atuais condições de saúde, para subsidiar melhores possibilidades, contribuindo para melhoria da qualidade de vida, quanto ao enfrentamento do processo de envelhecimento, a partir de um planejamento adequado (ALMEIDA et al, 2014).

Vale ressaltar que a saúde mental é uma prioridade para a saúde pública e exige dos gestores e serviços de saúde, estratégias criativas e que ocorram o mais breve possível, minimizando os agravos de diversas doenças psíquicas. Segundo Apóstolo et al. (2008), a depressão grave era uma das causas de incapacidade em todo o mundo, ocupando o quarto lugar entre as dez principais patologias. Não obstante, a Organização Mundial da saúde afirma que diante dos dados epidemiológicos crescentes, em 2020 essa doença será a mais incapacitante do mundo (VAZ et al., 2011).

Assim como a causa mais incapacitante de todo o mundo, a depressão, é também, a perturbação afetiva mais comum em idosos. Infelizmente, ainda com muita frequência, a depressão em idosos é subdiagnosticada e subtratada, o que pode ser caracterizado pela incapacidade de verbalizar as experiências afetivas (alexitimia), atingindo em sua maioria, os idosos institucionalizados. Outro grande motivo para o subdiagnóstico de depressão em idosos está relacionada às características dos sintomas depressivos, que por sua vez, podem ser confundidos com alguns tipos de demências decorrentes de outras doenças. (VAZ et al.,2011).

No âmbito das ILPIs, é imprescindível a avaliação psicológica com vistas à amplitude da saúde mental, pois ela contribui para a identificação de alterações que podem sinalizar patologias associadas, bem como atentar para variações cognitivas e de humor, importantes na manutenção da qualidade de vida desses indivíduos (MELO, 2011). Atingir maior grau de entendimento sobre a depressão em idosos, é extremamente importante na prática clínica, um 
mecanismo que contribui para evitar-se os agravos e consequências irrevogáveis, tais como os fatores de risco, inerentes da depressão. (OLIVEIRA,2006).

Partindo-se destes princípios, as assistências de enfermagem e de psicologia podem exercer papéis fundamentais, oferecendo práxis voltada ao envelhecimento saudável, compreendendo os fenômenos como eles se apresentam e assegurando o atendimento das necessidades do idoso, a fim de preservar a sua saúde e integridades física, mental, também, o aperfeiçoamento moral, intelectual, espiritual, estimulando condições de autonomia e dignidade (SILVA et al., 2012). O enfermeiro e o psicólogo enquanto profissionais presentes na equipe multidisciplinar, podem, através da abordagem gerontogeriátrica à depressão, ir além do convencional com enfoque apenas curativo.

Às ILPI são realizadas críticas quanto à maneira de cuidar, pois há as restrições e o controle através de regras aos idosos residentes nas mesmas, favorecendo ao isolamento e inatividade física e mental, favorecendo ainda mais para o desenvolvimento de doenças crônicas não transmissíveis (CAMARANO, 2010).

$\mathrm{Na}$ atualidade, observa-se entre os idosos uma cronicidade quanto a doenças, muitas vezes em comorbidade, também, problemas de ordem social, econômica, psicológica e nutricional, não raramente, podem se beneficiar de uma assistência interdisciplinar. A assistência ao idoso, é um processo interdisciplinar, sob a perspectiva multidisciplinar, com fim na manutenção de níveis normais de capacidade e autonomia, sem maiores prejuízos (ALMEIDA et al, 2014).

Nessa perspectiva, a assistência de enfermagem e de psicologia à estes idosos residentes em ILPIs necessitam de maior organização, principalmente, considerando-se as múltiplas necessidades como a melhoria no processo de trabalho e estrutural do ambiente comunitário, visando manter a dignidade, capacidade e participação democrática do idoso em seu próprio cuidado (SILVA, 2010).

\section{Metodologia}

Trata-se de uma revisão integrativa da literatura, que é considerada um instrumento da prática baseada em evidências (PBE), tem o potencial de construir conhecimento fundamentado e uniforme para a realização de uma prática clínica de qualidade, com o objetivo de proporcionar uma síntese dos conhecimentos e melhor aplicabilidade dos mesmos visando a 
compreensão da temática, a partir de outros estudos independentes. Esse método propõe o estabelecimento de critérios bem definidos sobre a coleta de dados, análise e apresentação dos resultados, desde o início do estudo, a partir de um protocolo de pesquisa previamente elaborado e validado (MENDES, 2008).

Foram adotadas as seis etapas indicadas para a constituição da revisão integrativa da literatura: 1) seleção da perguntas para a pesquisa; 2) definição dos critérios de inclusão de estudos e seleção da amostra; 3) representação dos estudos selecionados em formato de tabelas, considerando todas as características em comum; 4) análise crítica dos achados, identificando diferenças e conflitos; 5) interpretação dos resultados e 6) reportar, de forma clara, a evidência encontrada (SOUZA, 2010).

No presente estudo, optou-se por adotar para elaboração da questão norteadora, a estratégia PICO, que trata de acrônimo para Paciente, Intervenção, Comparação e Outcomes ou desfecho (GREENHALGH, 2005). Os termos utilizados nesta pesquisa foram: "P" Depressão em idosos asilados; "I" Metodologia que o cuidador deve utilizar para reduzir a depressão no idoso asilado; "C" os autores não têm objetivo de comparar intervenções; "O" O profissional auxiliando na prevenção e melhora do estado de depressão do idoso. Assim foi definida a questão norteadora: "Como prevenir e/ou diminuir o estado depressivo em idosos residentes em ILPIs"?

A estratégia de identificação e seleção dos estudos foi a busca de publicações indexadas na base de dados SCieLO (Scientific Eletronic Library), BVS (Biblioteca Virtual em Saúde) e LILACS (Literatura Latino-americana e do Caribe em Ciências da Saúde). Foram adotados os seguintes critérios para seleção dos artigos: todas as categorias de artigo (original, revisão de literatura, reflexão, atualização, relato de experiência etc.); aqueles publicados em português entre os anos 2000 e 2016 e que abordem a temática proposta no título e/ou resumo. Os critérios de inclusão adotados foram: artigos incompletos e repetidos nas bases de dados, sendo assim, selecionado apenas um dos arquivos repetidos.

A busca inicial possibilitou encontrar 565 artigos ao todo, dos quais apenas aqueles que que responderam aos objetivos e critérios de inclusão e exclusão foram selecionados para a realização da leitura minuciosa e consequentemente, utilizados como objetos de estudo por esta pesquisa. Deste modo, foram selecionados 4 da base de dados da SCieLO, 30 da LILACS e 531 da BVS. Como está disposto na Figura 1, a seguir 
Figura 1. Fluxograma com os quantitativos de artigos excluídos e incluídos na pesquisa.

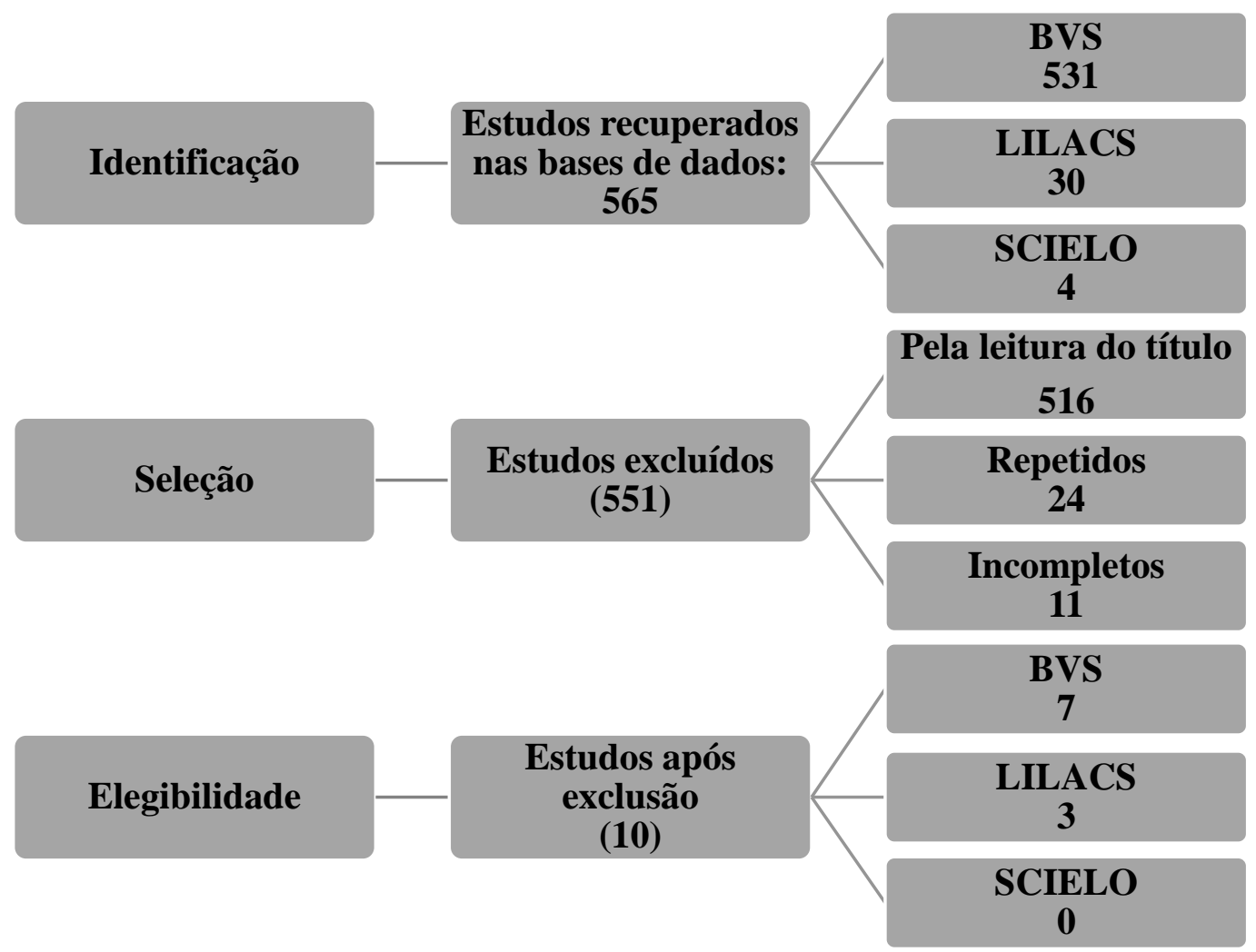

Os trabalhos foram comparados e agrupados por similaridade de conteúdo, sob a forma de categorias empíricas, sendo construídas duas categorias para análise, assim especificadas: depressão no idoso asilado e o papel cuidador e instituição, na prevenção e detecção da depressão no Idoso asilado.

\section{Resultados e Discussão}

Os artigos utilizados como objeto de estudo, foram publicados em diferentes periódicos sendo estes a Revista de Saúde Pública, Revista RENE, Psicologia: reflexões e química, Revista Bahiana de Saúde Pública, Ciência e Saúde Coletiva e Psicologia em estudo, ambas com apenas 1 artigo acerca da temática abordada, totalizando 6 artigos (60\%), 3 artigos (30\%) na Revista de Enfermagem e em 1 artigo (10\%), não foi possível identificar o periódico correspondente. 
Com relação à profissão dos autores, Enfermagem e Psicologia obtiveram o mesmo quantitativo de artigos, com $4(40 \%)$ cada, totalizando $80 \%$ das bibliográficas aqui utilizadas. Tais dados estão discorridos no quadro a seguir: 
Quadro 1. Instrumento utilizado para adscrever os artigos que foram selecionados como objetos de estudo.

\section{ARTIGOS SELECIONADOS}

\begin{tabular}{|c|c|c|c|c|c|c|c|c|}
\hline $\begin{array}{l}\text { Ordem de } \\
\text { classificação }\end{array}$ & Título & Autores & Ano & $\begin{array}{l}\text { Objeto } \\
\text { da } \\
\text { pesquisa }\end{array}$ & Periódicos & $\begin{array}{l}\text { Profissão } \\
\text { dos autores }\end{array}$ & Estado & Delineamento \\
\hline A1 & $\begin{array}{l}\text { "Prevalência de } \\
\text { depressão em } \\
\text { Idosos que } \\
\text { frequentam centros } \\
\text { de convivência." }\end{array}$ & $\begin{array}{l}\text { OLIVEIRA D. A. } \\
\text { A; } \\
\text { GOMES L.; } \\
\text { OLIVEIRA R. F. }\end{array}$ & 2006 & Idosos & $\begin{array}{l}\text { Rev. Saúde } \\
\text { Pública }\end{array}$ & $\begin{array}{l}\text { Não } \\
\text { encontrada }\end{array}$ & $\mathrm{DF}$ & $\begin{array}{l}\text { Descritivo } \\
\text { Transversal }\end{array}$ \\
\hline A2 & $\begin{array}{l}\text { "Sintomas } \\
\text { depressivos em } \\
\text { idosos: comparação } \\
\text { entre residentes em } \\
\text { condomínio } \\
\text { especifico para } \\
\text { idoso e na } \\
\text { comunidade." }\end{array}$ & $\begin{array}{l}\text { TESTONI, F. E.; } \\
\text { CARREIRAI, L.; } \\
\text { MACONI, S.S. }\end{array}$ & 2014 & Idosos & $\begin{array}{l}\text { Rev.. } \\
\text { Brasileira de } \\
\text { Enfermagem }\end{array}$ & Enfermagem & PR & Quantitativo \\
\hline A3 & $\begin{array}{l}\text { "Prevalência de } \\
\text { sintomatologia } \\
\text { depressiva em } \\
\text { idosos } \\
\text { institucionalizados." }\end{array}$ & $\begin{array}{l}\text { VERÇOSA, L. S. } \\
\text { V; CAVALCANTI, } \\
\text { L. S.; FREITAS, A. } \\
\text { D. }\end{array}$ & 2016 & Idosos & $\begin{array}{l}\text { Rev. de } \\
\text { Enfermagem }\end{array}$ & Enfermagem & $\mathrm{AL}$ & $\begin{array}{l}\text { Qualitativo, } \\
\text { transversal e } \\
\text { descritivo }\end{array}$ \\
\hline
\end{tabular}




\begin{tabular}{|c|c|c|c|c|c|c|c|c|}
\hline A4 & $\begin{array}{l}\text { "Qualidade de Vida, } \\
\text { Apoio Social e } \\
\text { Depressão em } \\
\text { Idosos: } \\
\text { Relação com } \\
\text { Habilidades } \\
\text { Sociais." }\end{array}$ & $\begin{array}{l}\text { CARNEIRO, S. R.; } \\
\text { FALCONE, E.; } \\
\text { CLARK, C. }\end{array}$ & 2008 & Idosos & $\begin{array}{l}\text { Psicologia: } \\
\text { Reflexão e } \\
\text { química }\end{array}$ & Psicologia & $\mathrm{RJ}$ & Qualitativa \\
\hline A7 & $\begin{array}{l}\text { "Relação entre } \\
\text { ansiedade, } \\
\text { depressão e } \\
\text { desesperança } \\
\text { Entre grupos de } \\
\text { idosos." }\end{array}$ & $\begin{array}{l}\text { OLIVEIRA, L. K; } \\
\text { SANTOS, A. A. A.; } \\
\text { CRUVENIL, M; } \\
\text { NÉRI, L. A. }\end{array}$ & 2006 & Idosos & $\begin{array}{l}\text { Psicologia } \\
\text { em Estudo }\end{array}$ & Psicologia & SP & $\begin{array}{l}\text { Qualitativa } \\
\text { analítica }\end{array}$ \\
\hline
\end{tabular}




\begin{tabular}{|c|c|c|c|c|c|c|c|c|}
\hline A8 & $\begin{array}{l}\text { "Transtornos } \\
\text { Depressivos em } \\
\text { idosos: O contexto } \\
\text { social e ambiente } \\
\text { como geradores." }\end{array}$ & $\begin{array}{l}\text { BRUNO, C. T. S.; } \\
\text { MARQUES, M. B.; } \\
\text { SILVA, M. J. }\end{array}$ & 2006 & Idosos & Rev. RENE & Enfermagem & $\mathrm{CE}$ & Quantitativa \\
\hline A9 & $\begin{array}{l}\text { "Prevalência de } \\
\text { sintomas } \\
\text { depressivos em } \\
\text { idosos } \\
\text { Institucionalizados } \\
\text { na cidade do } \\
\text { salvador." }\end{array}$ & $\begin{array}{l}\text { SANTANA, J. A.; } \\
\text { FILHO, B. C. J. }\end{array}$ & 2007 & Idosos & $\begin{array}{l}\text { Rev. } \\
\text { Bahiana de } \\
\text { Saúde } \\
\text { Pública }\end{array}$ & $\begin{array}{l}\text { Psquiatria e } \\
\text { Fisioterapia }\end{array}$ & BA & Transversal \\
\hline A10 & $\begin{array}{l}\text { "Prevalência de } \\
\text { depressão em } \\
\text { idosos } \\
\text { institucionalizados." }\end{array}$ & $\begin{array}{l}\text { CARREIRA, L.; } \\
\text { BOTELHO; R. M.; } \\
\text { MATOS, B. C. P.; } \\
\text { KORRES, M. M.; } \\
\text { SALCI, A. M. }\end{array}$ & 2011 & Idosos & $\begin{array}{l}\text { Rev. de } \\
\text { Enfermagem }\end{array}$ & Enfermagem & RJ & $\begin{array}{l}\text { Quantitativo, } \\
\text { descritivo e } \\
\text { explorativo. }\end{array}$ \\
\hline
\end{tabular}




\section{Depressão no idoso asilado}

Ao analisar os dados presentes nos artigos, foi possível perceber a grande frequência com que a depressão atinge os idosos que estão em centros de convivência, onde no artigo A1, 31\% dos idosos possuíam sintomatologia depressiva, utilizando a Escala de Depressão Geriátrica (EDG) na versão simplificada com 15 questões, como instrumento de pesquisa. Esse instrumento é validado e recomendado pela OMS (PARADELA, 2005). Essa escala simplificada (15 questões) também foi utilizada pelo A3 e A9, que apresentaram 58\% e 21,1\% respectivamente, de prevalência de sintomas depressivos. Já artigo A10 apresenta a versão da EDG com 30 questões e demonstrou $61,6 \%$ de quadros de depressão nos idosos institucionalizados.

No artigo A2, durante a coleta de dados, utilizou-se um instrumento multidimensional identificado como BOAS (BRAZIL OLD AGE SCHEDULE), que abrange diversas áreas da vida do idoso, passando pelos aspectos mentais e físicos, atividades do dia-a-dia e atual situação social e econômica e foi possível constatar a presença de depressão em 23,3\% dos idosos que moravam em um condomínio específico para idosos. Estes dados estão dispostos na figura 2 a seguir.

Figura 2. Revisão integrativa da literatura: porcentagem de depressão em idosos asilados afirmados e analisados nos artigos selecionados nas bases de dados da lilacs e bvs dos anos de 2006-2016. (PESQUEIRA, 2017)

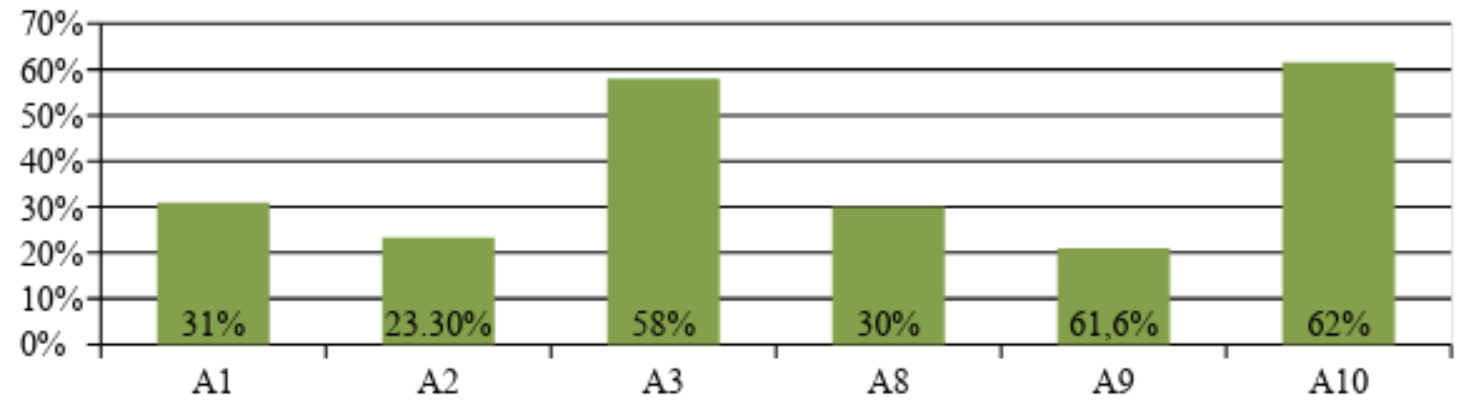


A grande maioria dos estudos aqui abordados (90\%) apresentaram idosos asilados com maior sintomatologia depressiva em relação aos idosos em convívio social e morando com a família. Apresentou-se apenas uma exceção: o A8 que obteve a constatação de que o idoso domiciliado sente-se mais desamparado quanto o que está asilado, possuindo maior grau de depressão em comparação um ao outro.

\section{O papel cuidador e instituição, na prevenção e detecção da depressão no Idoso asilado}

De acordo com os artigos analisados, A1 discorre a respeito grande necessidade, de que sejam criados programas nacionais em centros de convivência de idosos, para que seja possível, aperfeiçoar os conhecimentos por meio de cursos de extensão, especialização e envolvimento com atividades culturais de esporte e lazer.

Para A7 a prática de atividades física, por ser um hábito saudável, deve ser estimulada em qualquer faixa etária, e na velhice promove a boa manutenção da saúde física e mental. Tais atividades devem estar adequadas de acordo com as necessidades, condições de saúde e disponibilidade dos idosos em questão.

Os autores de A10 compreendem que o primeiro ano no asilo é um período de dificuldades em decorrência do processo de adaptação, a equipe responsável deve estar atenta e desenvolvendo atividades que contribuam para o melhoramento psíquico. Nessa perspectiva, A9 enfatiza para a importância da identificação dos sintomas e diagnostico precoce.

Os artigos A2 e A6 destacam que o enfermeiro, bem como toda a equipe multiprofissional, deverão estar capacitados para lidar com uma variabilidade da demanda em saúde, principalmente quanto às questões psicológicas da população idosa, uma vez que se desconhecidas, dificultam a prevenção, o diagnóstico e tratamento. Deve-se analisar também a critérios que transitam pela vida espiritual, amorosa e social dos idosos, e compreendam com maior especificidade a sintomatologia da depressão.

O estudo A3 defende que os profissionais de saúde atuantes nas instituições devem dispor de capacidades relacionadas a uma prática direcionada não apenas para detectar sintomas de depressão, mas qualquer outra alteração, compreendendo que velhice não é sinônimo de doença, mas que há uma maior predisposição. 
Como artigo voltado para profissionais de enfermagem, A5 discorre que o enfermeiro deve estar atento às particularidades de cada idoso de acordo com suas necessidades, principalmente em casos de transtornos mentais. Para A4, afirma que idosos institucionalizados são mais introvertidos e apresentam maiores dificuldades quanto às habilidades sociais, isso se deve ao fato de estarem em um ambiente que não lhes possibilitam atividades diversificadas, cabendo à instituição disponibilizar melhores condições de vida.

\section{Considerações Finais}

O idoso possui uma maior predisposição ao desenvolvimento de depressão pelo envelhecimento não saudável e incapacitante. Entretanto, os estigmas sociais envoltos no contexto das ILPIs podem potencializar sensações de aprisionamento, abandono e tristeza, aumentando assim a incidência de depressão neste público.

Nesta perspectiva, é imprescindível considerar que com fins a um atendimento focado no cuidado integral e especializado, as ILPIs precisam se adequar às necessidades dos idosos, tornando o ambiente mais sociável, familiar e com atenção qualificada, sendo uma proposta, incluir grupos de universitários para auxiliar neste enfrentamento. Além disso, percebe-se também a importância e a necessidade do convívio social extramuro das instituições, onde o idoso possa ser ativo em seu processo vital, fazendo com que o mesmo diminua os seus sentimentos de impotência, angústia e introspecção.

A análise crítica dos artigos possibilitou perceber que os membros da equipe multiprofissional e/ou cuidadores profissionais do idoso precisam estar atentos aos sintomas da depressão, para que a mesma seja detectada precocemente. Além disso, é necessário compreender a multicausalidade desse transtorno mental, fazendo com que as práticas de promoção e prevenção da saúde também sejam multifacetadas, com a inserção de práticas de atividade física, jogos, passeios e alternativas de entretenimento para o idoso.

Esta pesquisa não esgota a temática, sendo necessária cada vez mais a busca por melhores condições de atenção ao idoso residente em ILPI, entretanto, contribuiu para a sinalização e a percepção da importância do cuidado a saúde mental do idoso, que não deve ser negligenciada. Como proposta para novas pesquisas, acena-se para situações exitosas e a busca por instrumentos de avaliação gerontológica global em residentes de ILPIs, focando na detecção 
precoce da depressão com maior eficácia e melhorias baseadas na individualidade de cada idoso.

\section{Referências}

ALMEIDA, M. F. I. et al. Depressão do idoso: o papel da assistência de enfermagem na recuperação dos pacientes depressivos. Revista Eletrônica Interdisciplinar, v. 1, n. 11, 2014.

APÓSTOLO, J. et al. Depressão, ansiedade e stresse em utentes de cuidados de saúde primários. Referência. Série 2, no 2, p. 46. 2008.

BRASIL. (2005). Resolução RDC n. ${ }^{\circ} 283$ de 26 de setembro de 2005. Aprova o Regulamento Técnico que define normas de funcionamento para as Instituições de Longa Permanência para Idosos. Diário Oficial da República Federativa do Brasil, Brasília (DF), 26 set. 2005 Seção 1: 58. Disponível em: http://bvsms.saude.gov.br/bvs/saudelegis/anvisa/2005/res0283_26_09_2005.html.

BRUNO, C. T. S.; MARQUES, M. B.; SILVA, M. J. Transtornos depressivos em idosos: o contexto social e ambiente como geradores. Revista da rede de enfermagem do Nordeste, $v$. 7, n. 1, 2006. VIEIRA, C.S; Atividades/ Interação dos idosos institucionalizados com a comunidade. Universidade Fernando Pessoa. Ponte Lima, 2015.

CAMARANO, A. A; Cuidados de longa duração para a população Idosa: um novo risco social a ser assumido? Rio de Janeiro, 2010. Disponível em: Acesso em: 26 mai. 2017.

CARREIRA, L. et al. Prevalência de depressão em idosos institucionalizados. Rev. enferm. UERJ, v. 19, n. 2, p. 268-273, 2011.

CARNEIRO, R. S. et al. Qualidade de vida, apoio social e depressão em idosos: relação com habilidades sociais. Psicologia: reflexão e crítica, v. 20, n. 2, p. 229-237, 2007.

CORTEllEtTI, I. A.; CASARA, M. B.; HEREDIA, V.B. Idoso Asilado: um estudo Gerontológico, p. 134. Caxias do Sul, 2010.

GREENHALGH, T. Como ler artigos científicos: fundamentos da medicina baseada em evidências. 2a . Ed.- Porto Alegre : Artmed, 2005.

IBGE- Instituto Brasileiro de Geografia e Estatística. Pesquisa Nacional por Amostra de Domicílios. Síntese dos Indicadores de 2009. Rio de Janeiro, 2010.

LIMA, P. et al. Depressão, um sofrimento sem fronteira: representações sociais entre crianças e idosos. Revista Psico-USF, v. 8, n. 2, p. 183-192, 2003.

LISBOA, C.R.; CHIANCA, T.C.M. Perfil epidemiológico, clínico e de independência funcional de uma população idosa institucionalizada. Revista Brasileira de Enfermagem. v. 65, 
n. 3, p. 482-487. Brasília, 2012.

LOURENÇO, T. M. et al. Capacidade funcional no idoso longevo: uma revisão integrativa. Revista Gaúcha de Enfermagem, v. 33, n. 2, p. 176-185, 2012.

MATOS, D. M.; OLCHIK, M. R. Impacto da fragilidade na depressão e na cognição em idosos institucionalizados. UFRG, 2016.

MENDES, K. D. S.; SILVEIRA, R. C. C. P.; GALVÃO, C. M. Revisão integrativa: método de pesquisa para a incorporação de evidências na saúde e na enfermagem. Texto \& Contexto Enferm. v.17, n.4, p.58-64, 2008.

MELO, D. K. N. et al. Indicadores de depressão em idosos institucionalizados. Cogitare Enfermagem, v. 16, n. 3, 2011.

MINGHELLI, B. et al. Comparação dos níveis de ansiedade e depressão entre idosos ativos e sedentários. Revista de Psiquiatria Clínica, v. 40, n. 2, p. 71-76, 2013.

O GLOBO. Mais de 75 mil pessoas foram afastadas do trabalho por depressão em 2016. Época Negocios. 12 de fevereiro de 2017. Disponível em: https://epocanegocios.globo.com/Carreira/noticia/2017/02/mais-de-75-mil-pessoas-foramafastadas-do-trabalho-por-depressao-em-2016.html Acesso em: 24 de fevereiro de 2018.

OLIVEIRA, K. L. et al. Relação entre ansiedade, depressão e desesperança entre grupos de idosos. Psicol Est, v. 11, n. 2, p. 351-9, 2006.

OLIVEIRA, D. A. A. P.; GOMES, L.; OLIVEIRA, R. F. Prevalência de depressão em idosos que freqüentam centros de convivência. Rev Saúde Pública, v. 40, n. 4, p. 734-6, 2006.

PARADELA, E. M. P.; LOURENÇO, R. A.; VERAS, R. P. Validação da escala de depressão geriátrica em um ambulatório geral. Revista de Saúde Pública. V. 39, n.6, p.918-923, 2005.

PORCU M, S. V M; ALBRECHT,N. R.; SILVA, S. P.; VALLIM, F. L.; ARAÚJO, C. R.; DELTREGGIA, C. F. , FAIOLA, R. V. Estudo comparativo sobre a prevalência de sintomas depressivos em idosos hospitalizados, institucionalizados e residentes na comunidade. Acta Sci. v. 24, n.3, p.713-717, 2002.

RIBEIRO, O. O envelhecimento "ativo" e os constrangimentos da sua definição. Sociologia, Revista da Faculdade de Letras da Universidade do Porto, p. 33-52, 2012.

ROESLER, E. et al. Prevalência e fatores associados à depressão entre idosos institucionalizados: subsídio ao cuidado de enfermagem. Revista da Escola de Enfermagem da USP, v. 46, n. 6, p. 1387-1393, 2012.

SANTANA, A. J.; BARBOZA, J. C. F. Prevalência de sintomas depressivos em idosos institucionalizados na cidade do Salvador. Rev. baiana saúde pública, v. 31, n. 1, p. 134-146, 2007. 
SANTOS, Maria Izabel Penha de Oliveira et al. Capacidade funcional de idosos atendidos em um programa do SUS em Belém (PA). 2013.

SANTOS FERREIRA, Pollyana Cristina et al. Características sociodemográficas e hábitos de vida de idosos com e sem indicativo de depressão. Revista Eletrônica de Enfermagem, v. 15, n. 1, p. 197-204, 2013.

SIQUEIRA, Gisela Rocha de et al. Análise da sintomatologia depressiva nos moradores do Abrigo Cristo Redentor através da aplicação da Escala de Depressão Geriátrica (EDG). Ciênc saúde coletiva, v. 14, n. 1, p. 253-9, 2009.

SOUZA, M. T.; SILVA, M. D.; CARVALHO, R.. Revisão integrativa: o que é e como fazer. Einstein (São Paulo), v. 8, p. 102-106, 2010.

TESTON, Elen Ferraz; CARREIRA, Ligia; MARCON, Sonia Silva. Sintomas depressivos em idosos: comparação entre residentes em condomínio específico para idoso e na comunidade/Depressive symptoms in the elderly: comparison of residents in condominium specific for elderly and in the community/Síntomas depresivos en personas mayores: comparación entre los residentes en condominio específico para ancianos y en la comunidad. Revista Brasileira de Enfermagem, v. 67, n. 3, p. 450, 2014.

VERAS, R. P. Experiências e tendências internacionais de modelos de cuidado para com o idoso International Experiences and Trends in Health Care Models for the Elderly. Ciência \& Saúde Coletiva, v. 17, n. 1, p. 231-8, 2012.

VIEIRA, C.S; Atividades/ Interação dos idosos institucionalizados com a comunidade. Universidade Fernando Pessoa. Ponte Lima, 2015.

VAZ, S. F. A.; GASPAR, N. M. S. Depressão em idosos institucionalizados no distrito de Bragança. Revista de Enfermagem Referência, n. 4, p. 49-58, 2011.

VERÇOSA, V. S. L.; CAVALCANTI, S. L.; FREITAS, D. A. Prevalência de sintomatologia depressiva em idosos institucionalizados. Revista de enfermagem UFPE on line-ISSN: 19818963, v. 10, n. 5, p. 4264-4270, 2016.

ZAGONEL, A. D. et al. As percepções sociais frente a implantação de uma Instituição de Longa Permanência para Idosos em um município do Vale do Taquari/RS, Brasil. Scientia Plena, v. 13, n. 2, 2017.

\section{Como citar este artigo (Formato ABNT):}

VERAS, samara M. de J.; SILVA, Werika S.B. da; LEITE-SALGUEIRO, Cláudia D.B. Produção Científica sobre Saúde Mental de Idosos Residentes em Instituições de Longa Permanência. Id on Line Rev.Mult. Psic., 2018, vol.12, n.40, p.336-352. ISSN: 1981-1179.

Recebido: 24/03/2018

Aceito 29/03/2018 